\title{
HEARING DUE TO ELECTRICAL STIMULATION OF THE AUDITORY SYSTEM
}

\author{
Graeme M. Clark, M.s., f.r.c.s. (edin.), h.R.c.s., F.R.a.c.s. \\ Brain Research Unit, Department of Physiology, University of Sydney
}

ONE of the major problems facing otologists today is the treatment of perceptive deafness. The results of treating patients with deafness due to middle-ear disease are now good, but this is not the case when there is damage to the inner ear or central auditory pathways. A hearing aid will assist a great many people, but there are a number of patients with very severe or total deafness who cannot be helped in this way. Consequently, a different approach to the problem must be made, and for this reason, electrical stimulation of the cochlea or auditory pathways to reproduce the natural stimulus may provide a solution.

Various forms of electrical stimulation have been used for nearly two centuries in the hope that hearing could be reproduced artificially. The first recorded attempt was made by Volta (1800), who connected a battery of 30 or 40 "couples" to two metal rods which were inserted into his ears. When the circuit was completed, he received "une secousse dans la tête" and a few moments later a noise like the boiling of thick soup.

In spite of the unpleasant sensation experienced, sporadic attempts to investigate the phenomenon were carried out during the next 50 years, but the sensation produced was always momentary and lacked tonal quality.

As sound is an alternating disturbance in air, it was soon appreciated that stimulating the auditory system with a direct current could not reproduce a satisfactory hearing sensation. Consequently, Duchenne of Boulogne (1855) stimulated the acoustic apparatus with an alternating current which he produced by inserting a vibrator into a circuit containing a condenser and induction coil. The result, however, was still not satisfactory, as he only experienced a sound which resembled "the beating of a fly's wings between a pane of glass and a curtain" (Scheppegrell, 1898).

Renewed interest in the problem of reproducing learing artificially occurred with the introduction of the thermionic valve, which enabled the auditory system to be stimulated electrically with much greater precision. This work was also encouraged by the demonstration by Wever and Bray (1930) that the electrical response recorded from the vicinity of thc auditory nerve of a cat was similar in frequency and amplitude to the sounds to which the ear had been exposed.

At this time, Russian investigators were among the first to examine the effects of an alternating electrical stimulus on hearing. A report by Gersuni and Volokhov (1936) indicated that the hearing sensation was usually very clear and that speech could be understood. These results, however, were obtained only in patients with normal or some residual hearing. It became evident that, in many cases, electrical energy was transduced into sound vibrations before it reached the inner ear. Some nice work was done by Jones et alii (1940) which established this fact, and hearing induced in this way has been called the electrophonic effect

In the course of this research into electrophonic hearing, it became apparent that total perceptive deafness could not be corrected by inducing a widespread electrical field in the region of the inner ear, but that more localized stimulation of the auditory nerve fibres was required.

One of the first recorded attempts to stimulate the auditory nerve was made in 1950 by Lundberg (Gisselsson, 1950), who stimulated the nerve during a neurosurgical operation. The patient, however, could only experience 
noise. A more detailed study was performed by Djourno and Eyries (1957), and the stimulus parameters appear to have been well controlled. In their study, the electrode was placed on the patient's auditory nerve, which was exposed during an operation for cholesteatoma. The patient was able to appreciate differences in pitch in increments of 100 pulses per second up to a frequency of 1,000 pulses per second. He was also able to distinguish certain words such as "papa", "maman", and "allo".

It appeared flom these studies that electrical stimulation of the auditory nerve could not reproduce frequencies above $1,000 \mathrm{cps}$, which are necessary if speech is to be comprehended. This failure to respond to higher frequencies was due to the fact that the auditory nerve, because of its refractory period, is like other nerves in the body and cannot be stimulated more rapidly than 1,000 per second. Although a nerve fibre will not fire more rapidly than a rate of 1,000 per second, it can fire in phase to stimuli of up to $5,000 \mathrm{cps}$ (Rose et alii, 1967). This means that in response to a 5,000 cps tone, an auditory nerve fibre could fire every fifth cycle of the stimulus at a constant phase of the sine wave. If we consider a large population of nerve fibres, each responding to a $5,000 \mathrm{cps}$ tone, some will fire every cycle.

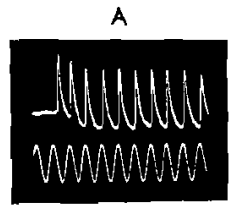

$500 \mathrm{cps}$

D

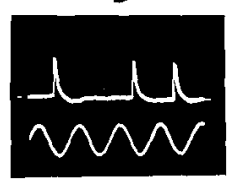

$200 \mathrm{cps}$

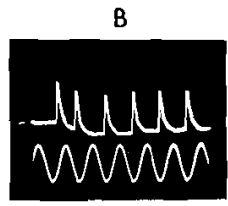

$300 \mathrm{cps}$

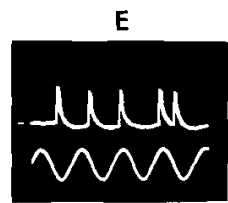

$200 \mathrm{cps}$

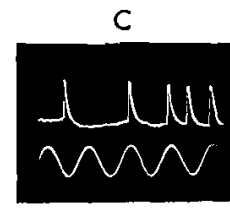

200 cps
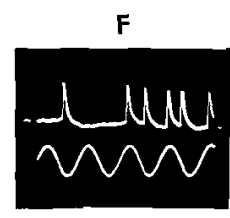

200 cps
Figure 1: Cellular action potentials from the superior olivary complex of the cat in response to frequencies of 200,300 and $500 \mathrm{cps}$.

This concept of a phase-locked response is illustrated in Figure 1. These records were obtained from the superior olivary complex of the cat, a second-order relay station along the central auditory pathways, and were in response to frequencies of 200,300 and $500 \mathrm{cps}$. The bottom trace in each case is the sinusoidal sound wave, and the top trace is the action potential. It can be seen that for a stimulus of 300 and $500 \mathrm{cps}$, an action potential occurs at the same point on each sine wave, that is, it is phase-locked. Because the $200 \mathrm{cps}$ stimulus was outside the characteristic range of the cell, it did not produce an action potential with each cycle, and sometimes two occurred together; but they were still locked to a particular phase of the sine wave. Although it is more difficult to demonstrate, similar phase-locking of action potentials to every second, third or fourth cycle can occur for high frequencies. This ability of nerve fibres and cells to fire in phase to a sound wave could explain how frequency is coded. and is the basis of the volley theory of hearing.

Consequently, if the auditory nerve is to be stimulated in accord with the volley theory, an electrical stimulus must be found which will cause the nerve cells to fire in phase, but not necessarily with each cycle, so that a response to high rates of stimulation can be obtained

Information about the frequency of a sound may also be conveyed to the brain on the basis of the place theory. In this case, it does not matter if the nerve cells fire in phase with the sine wave, but it is important to stimulate the correct nerve cells. The hearing receptors in the inner ear and the cells and fibres in the central nervous system will respond only to a limited range of frequencies. These cells and fibres are also arranged in an orderly, anatomical way so that a frequency scale from low to high is preserved. This means that if we want to reproduce a 5,000 cps tone artificially by electrical stimulation, those auditory nerve fibres should be stimulated which normally convey this information. This may be done surgically by placing electrodes close to the auditory nerve fibres where they can fan out to supply the organ of hearing in the inner ear.

This was performed by Simmons et alii (1965), who implanted six electrodes in the modiolus of the cochlea of a patient who was stone deaf. The appropriate electrodes were stimulated electrically, but the subject could perceive only a limited range of frequencies, and speech comprehension was poor. With some training, he could recognize tunes such as "Three Blind Mice" and definitely preferred to have the apparatus switched on so that he could hear sound, even though it was distorted.

This study of Simmons et alii (1965) appears to have been well controlled, and indicates that there are still many problems that must be solved before adequate hearing can be produced by electrical stimulation of the auditory nerve. These problems are not just limited to the auditory system, but affect the general somatic system as well (Frank, 1968), in which the difficulties are also great, but not without solution.

In an attempt to answer some of these problems, I have performed experiments on cats (Clark, 1969). The auditory nerve and cochlea have been stimulated electrically and responses recorded from a secondary relay nucleus in the central nervous system, the superior olivary complex. The responses, recorded with an electrical stimulus of a certain rate, have been compared with the response obtained for a sound of the same frequency. In this way, variations in the method of electrical stimulation have been compared in order to see whether electrical stimulation can satisfactorily reproduce sound.

The response pattern of a cell to a number of stimuls has been obtained by measuring the probability of a cell firing following the onset of the stimulus. This response pattern is called a poststimulus histogram, and its shape can vary for different cells and in different nuclei (Clark and Dunlop, 1969). Examples of different poststimulus histograms in the three main subdivisions of the superior olivary complex can be seen in Figure 2 .

This work has shown that the experimental animal can be used to test different electrode systems, and provides good evidence of their effectiveness in reproducing sound. This will reduce the necessity to operate on patients during the developmental stage of this work.

The work indicates that, at the moment, only certain aspects of sound can be reproduced with an electrical 
stimulus, and that stimulation on the basis of the place theory is most likely to prove effective. More research is required, however, to produce an entirely satisfactory method of stimulation, and it is to be hoped that in the
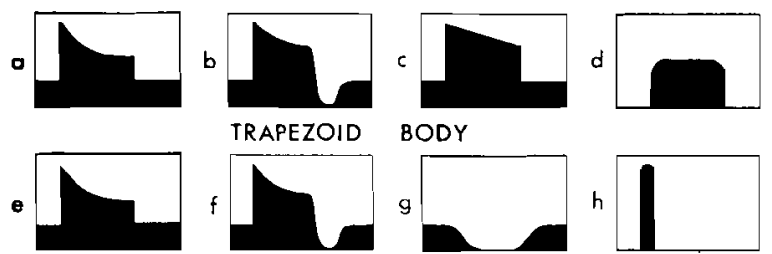

BODY

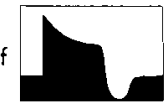

9

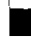

MEDIAL SUPERIOR OLIVE
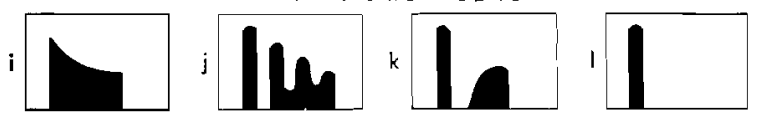

LATERAL SUPERIOR OLIVE

Figure 2: Poststimulus histograms of cellular response patterns to tone pulses, recorded from the three main patterns to tone pulses, recorded from the three main
subdivisions of the superior olivary complex of the cat.

next few years developments in basic neurophysiology will occur concurrently with improvements in technology. Nevertheless, an optimistic view can be taken about the eventual outcome.

\section{ACKNOWLEDGEMENTS}

The National Health and Medical Research Council of Australia provided funds for this research. My thanks go to Associate Professor C. W. Dunlop for his support and interest in this study. I should like to thank Miss $J$. Harvey for technical assistance, Mr E. Fuster for photographic help and Miss $R$. Swan for the typing.

\section{REFERENCES}

Clark, G. M. (1969), "The Response of Cells in the Superior Olivary Complex of the Cat to Electrical stimulation of the Auditory Nerve", Exp. Neurol., in the press.

Clark, G. M., and Dunlop, C. W. (1969), "Postgtimulus-time Response Patterns in the Nuclei of the Cat Superior Olivary Complex", Exp. Neurol., 23: 266.

Djourno, A., and Eyries, CH. (1957), "Prosthèse auditive pa, excitation électrique a distance du nerf sensoriel $a$ l'aid $d^{\prime} u n$ bobinage inclus à demeure", Presse méd., 65: 1417

Frank, K. (1968), "Some Approaches to the Technical Problem of Chronic Excitation of Peripheral Nerve", Ann. Otol. (St Louis), 77: 761 .

GRRSUNi, C. V., and VoLokHov, A. A. (1936), "On the Electrlcal Excitability of the Auditory Organ: 'On the Effect of Alternating Currents on the Normal Auditory Apparatus", J. exp. Psychol., 19:370.

Gisselsson, L. (1950), "Experimental Investigation into the Problem of Humoral Transmission in the Cochlea". Acta oto-laryng. (Stockh.), Suppl. 82:16.

Jones, R. C., Stevens, S. S., and Lurie, M. H. (1940), "Three Mechanisms of Hearing by Electricai Stimulation", $J$. acoust. Soc. Amer., 12:281.

ROSE, J. F., BRUGGE, J. F., ANDERsON, D. J., and HIND, J. E. (1967), "Phase-Locked Response to Low-Frequency Tones in Single Auditory Nerve Fibers of the Squirrel Monkey", $J$. Nenrophysiol., 30: 769 .

SCHEPPEGRELL, W. (1898), "Electricity in Diseases of the Nose, Throat and Ear", Putnam's Sons, New York.

Simmons, F. B., Epley, J. M., Lommis, R. C., Guttman, N., FRISHKOPF, L. S., HARMAN, L. D., and ZWICKER, E. (1965) "Auditory Nerve: Electrical Stimulation in Man", Science, $148: 104$.

Volta, A. (1800), "On the Electricity Exclted by Mere Contac of Conducting Substances of Different Kinds", Roy. Soc.

Wever, E. G., and Brat. C. W. (1930), "Auditory Nerve Impulses", Science, 71 : 215. 


\section{University Library}

\section{- M M I E R R V A gateway to Melbourne's research publications}

Minerva Access is the Institutional Repository of The University of Melbourne

Author/s:

Clark, Graeme M.

Title:

Hearing due to electrical stimulation of the auditory system

Date:

1969

Citation:

Clark, G. M. (1969). Hearing due to electrical stimulation of the auditory system. Medical Journal of Australia, June, 1, 1346-1348.

Persistent Link:

http://hdl.handle.net/11343/27109 